\title{
Core Biopsy
}

National Cancer Institute

\section{Source}

National Cancer Institute. Core Biopsy. NCI Thesaurus. Code C15680.

The removal of a tissue sample using a needle with a relatively large diameter, for microscopic examination. 